\title{
Challenges of CPAS Flight Testing
}

\author{
Eric S. Ray ${ }^{1}$ \\ Jacobs ESCG, Houston, TX, 77598 \\ Aaron L. Morris ${ }^{2}$ \\ Barrios Technology, Houston, TX, 77598
}

The Crew Exploration Vehicle Parachute Assembly System (CPAS) is being designed to land the Orion Crew Module (CM) at a safe rate of descent at splashdown via a series of Drogue, Pilot, and Main parachutes. Because Orion is considerably larger and heavier than Apollo, many of the flight test techniques developed during the Apollo program must be modified. The Apollo program had a dedicated C-133 aircraft, which was modified to allow a simple airdrop of "boilerplate" flight test vehicles. However, the CPAS program must use either commercial or military assets with minimal modifications to airframes or procedures. Conceptual envelopes from 2-Degree Of Freedom trajectories are presented for several existing and novel architectures. Ideally, the technique would deliver a representative capsule shape to the desired altitude and dynamic pressure at test initiation. However, compromises must be made on the characteristics of trajectories or the fidelity of test articles to production hardware. Most of the tests to date have used traditional pallet and weight tub or missile-shaped test vehicles. New test vehicles are being designed to better incorporate Orion structural components and deploy parachutes in a more representative fashion. The first attempt to test a capsule-shaped vehicle failed due to unexpected events while setting up the test condition through a series of complex procedures. In order to avoid the loss of another expensive test article which will delay the program, simpler deployment methods are being examined and more positive control of the vehicle will be maintained. Existing challenges include interfacing with parent aircraft, separating test vehicles, achieving test conditions, and landing within limited test ranges. All these challenges must be met within cost and schedule limits.

\section{Nomenclature}

$\begin{array}{ll}\text { ARD } & =\text { Atmospheric Reentry Demonstrator } \\ \text { CDT } & =\text { Cluster Development Test (series) } \\ \text { CEV } & =\text { Crew Exploration Vehicle } \\ \text { CG } & =\text { Center of Gravity } \\ \text { CM } & =\text { (Orion) Crew Module or (Apollo) Command Module } \\ \text { CMS } & =\text { Cradle Monorail System } \\ \text { CPAS } & =\text { Crew Exploration Vehicle Parachute Assembly System } \\ \text { CPSS } & =\text { Cradle and Platform Separation System } \\ \text { DDT } & =\text { Drogue Development Test (series) } \\ \text { DOF } & =\text { Degree Of Freedom } \\ \text { DTV } & =\text { Drop Test Vehicle } \\ \text { DZ } & =\text { Drop Zone } \\ \text { EDU } & =\text { Engineering Development Unit } \\ \text { esa } & =\text { European Space Agency } \\ \text { ESCG } & =\text { Engineering Services Contract Group }\end{array}$

\footnotetext{
${ }^{1}$ Analysis Engineer, Aerothermal and Flight Mechanics, 455 E. Medical Center Blvd., Webster, TX, AIAA Member.

${ }^{2}$ CPAS Analysis IPT Chair, Aerothermal and Flight Mechanics, 455 E. Medical Center Blvd., Webster, TX, AIAA Senior Member.
} 


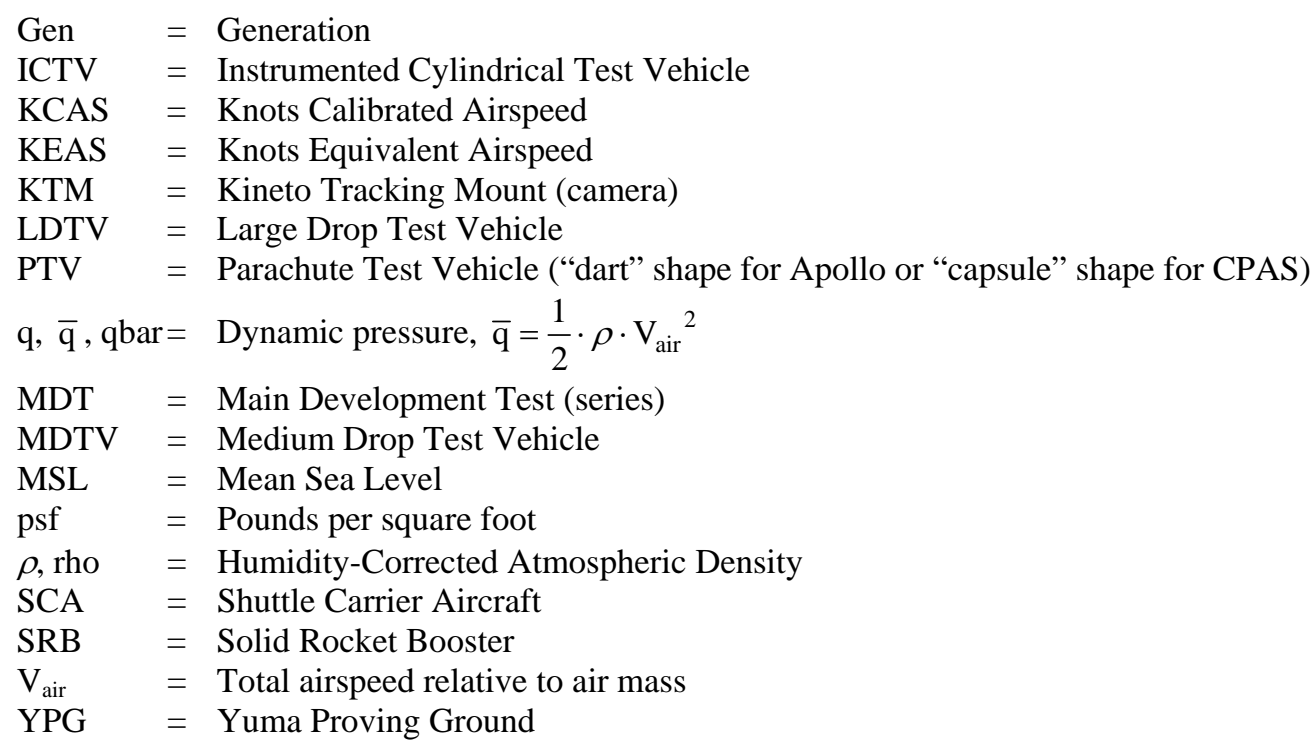

\section{Introduction}

$\mathrm{T}$ HE Crew Exploration Vehicle (CEV) Parachute Assembly System (CPAS) must demonstrate the ability to safely land its crew through flight testing. The CEV was described as "Apollo on steroids." As the CEV changed into the current Orion Crew Module (CM), many of the original capabilities were scaled down, but the physical differences between Apollo and Orion are still apparent, as shown in Figure 1. ${ }^{(1)}$ The final Apollo design was 105 inches tall with a maximum diameter of 154 inches. The current Orion design is about 142 inches tall with a diameter of about 217 inches. It will be shown that the larger diameter of the parachute compartment becomes a particular issue with aircraft interfaces during flight testing.

The current Orion landing system architecture is similar to Apollo, as shown in Figure 2. ${ }^{(2)}$ Both systems use two mortar-deployed drogue parachutes for initial deceleration. Then three mortar-deployed pilot parachutes each lift and deploy a main parachute. Each system is intended to be robust enough to land safely should either a single drogue or single main parachute fail to function.

To human rate the landing system, flight tests need to test representative hardware under realistic conditions. The drogue deployment envelopes for Apollo and CPAS are compared in Figure 3. Getting a test article to the high altitudes and dynamic pressures that would be seen during reentry presents a challenge to any parent vehicle short of a rocket.

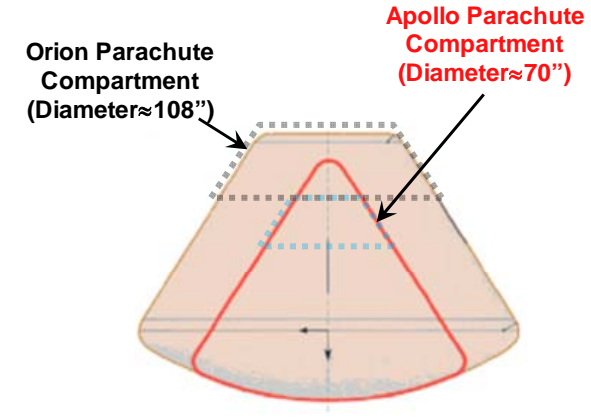

Figure 1. Dimension comparison between Orion and Apollo capsules.

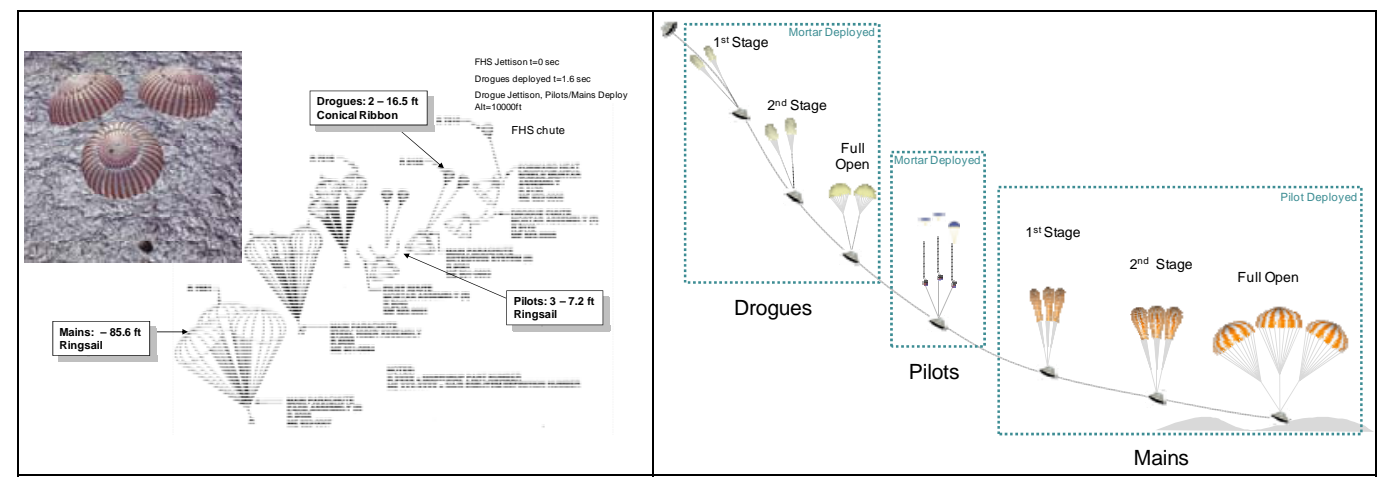

Figure 2. Apollo and CPAS parachute sequences. 


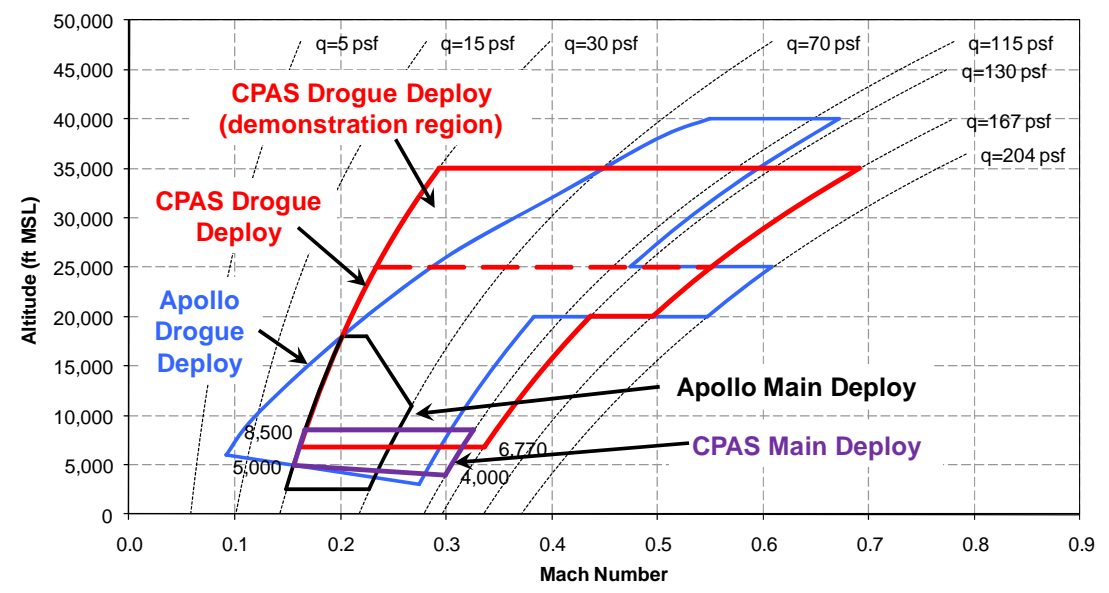

Figure 3. Parachute Deploy Envelope Comparison.

\section{Apollo Test Vehicles}

The Apollo test program was broken into three blocks. The final phase, Block II Increased Capability, consisted of 38 flight tests, including 7 qualification flight tests of operationally representative hardware. This paper will focus on this block because it is similar in scope to CPAS. Several types of parent aircraft and test articles were used during Apollo flight testing. A summary of the release conditions of these tests is shown in Figure $4 .{ }^{(3)}$ Note that the actual parachute system initiation generally occurred at lower altitudes when the test articles accelerated to the proper test conditions.

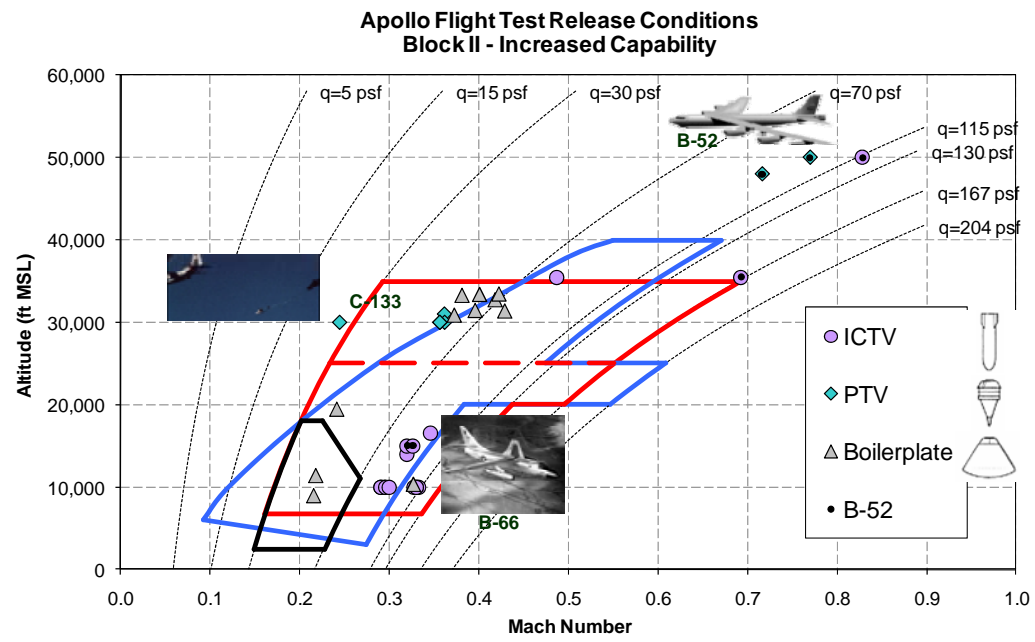

Figure 4. Apollo Block II Increased Capability test release conditions. 


\section{A. Instrumented Cylindrical Test Vehicle (ICTV) and Parachute Test Vehicle (PTV)}

The simplest test article was a bomb-shaped device about 160 inches long with a diameter of about 35 inches, designated Instrumented Cylindrical Test Vehicle (ICTV). The robust design and inexpensive construction, shown in Figure 5, was idealized for conducting overload testing. The ICTV was dropped from both a B-66 and the bomb bay of a B-52. Due to its shape, it could accelerate to a high dynamic pressure. However, the Apollo parachute deployment methods could not be replicated on the ICTV, so additional test vehicles were needed.

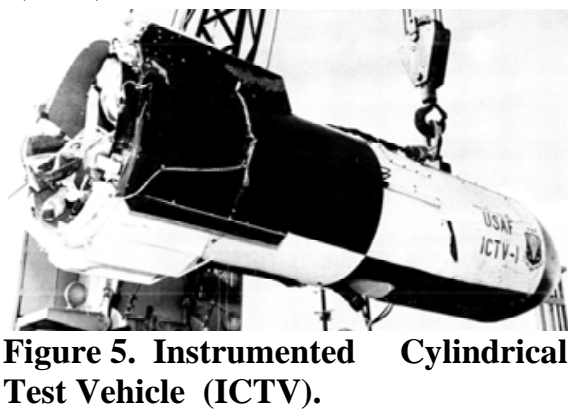

The Parachute Test Vehicle (PTV) was designed to have the complete parachute system attached to a ruggedized structure as shown in Figure 6. The vehicle was streamlined and heavily ballasted to achieve high dynamic pressures at drogue mortar firing. The PTV

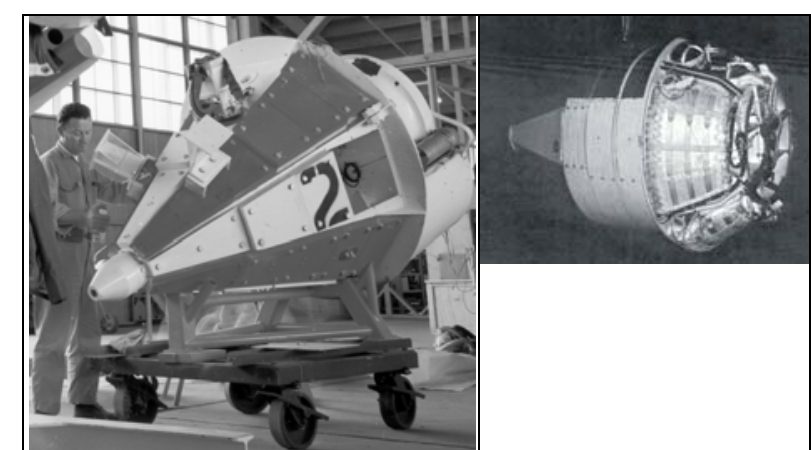

Figure 6. Parachute Test Vehicle (PTV).

was about 128 inches long with a diameter equal to the Parachute Subsystem upper deck of about 70 inches. The entire parachute sequence could be conducted and the system would descend carrying the correct Apollo weight under clusters of either two or three main parachutes, as shown in Figure 7.

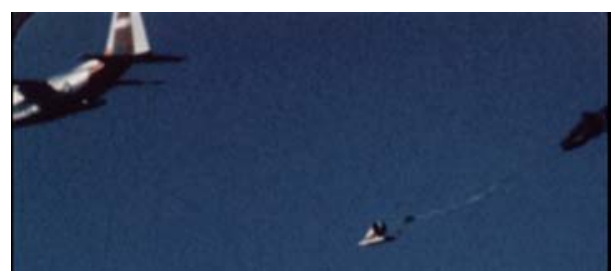

Figure 8. PTV extraction from C-133.

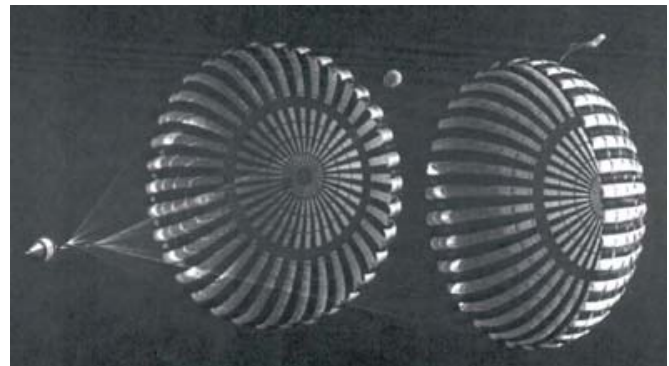

Figure 7. Main parachutes deployed from PTV during Drop Test 84-4.

The PTV was compatible with two parent aircraft, depending on the test requirements. Low altitude tests could be conducted by extracting the PTV on a sled from a C-133 Cargomaster. This technique is shown in Figure 8. The ballasted nose of the PTV allowed for a stable separation from the extraction pallet.

Higher altitude tests required a B-52. The diameter of the PTV was just able to fit inside the bomb bay. 


\section{B. Boilerplate}

Several buildup tests and all qualification tests were conducted using "boilerplate" capsules, which simulated the physical characteristics of the Apollo Command Module, including the production parachute system. These boilerplates were released from a modified Douglas C-133 Cargomaster, similar to the contemporary Lockheed C130 Hercules. The cargo ramp was removed and an internal cantilevered truss held the capsule, as seen in Figure 9.

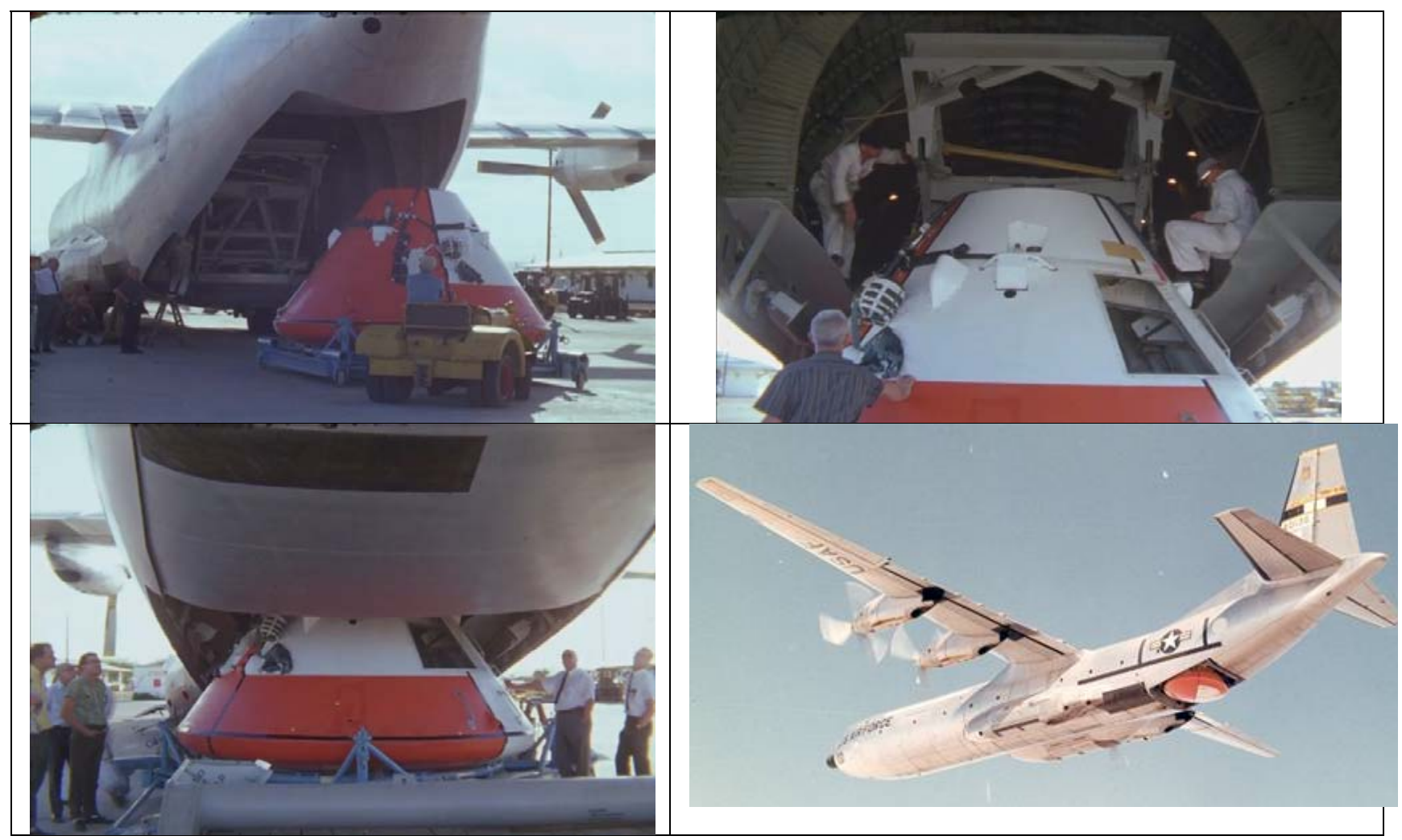

Figure 9. Apollo boilerplate capsule loaded on to modified C-133 parent aircraft. 
This drop test method allowed the Apollo boilerplate to test the complete Parachute Subsystem for nominal reentry trajectories as well as failure modes. Representative trajectories for three of the seven Block II Increased Capability qualification tests are plotted in Figure 10. ${ }^{(4)}$ Mach number and KCAS were computed from dynamic pressure and altitude data using the 1976 standard atmosphere.

Test number 85-4 (Figure 10a) was set up to simulate the nominal reentry but with a programmed cartridge failure in one drogue mortar. The boilerplate was dropped from the C-133 at 33,438 ft MSL and about 136 KCAS and deployed a programmer parachute by static line. The programmer cut away for drogue mortar fire in the center of the deploy envelope.

Test 85-6 (Figure 10b) simulated a pad abort and manual override of the drogue parachutes. The boilerplate was released at 10,371 $\mathrm{ft}$ MSL and about 179 KCAS without a programmer parachute. The boilerplate pitched to the desired horizontal attitude at pilot mortar fire.

Test 85-7 (Figure 10c) simulated a high altitude abort scenario with programmed failures of one drogue and one pilot parachute. Release conditions were $32,802 \mathrm{ft}$ MSL and about 144 KCAS. The programmer imparted an apex forward attitude. The boilerplate completed a gravity turn while decelerating under the programmer, which then disconnected. The boilerplate remained apex forward during freefall for 15 seconds to build up speed and deploy the drogues near the center of the drogue deploy "shelf."
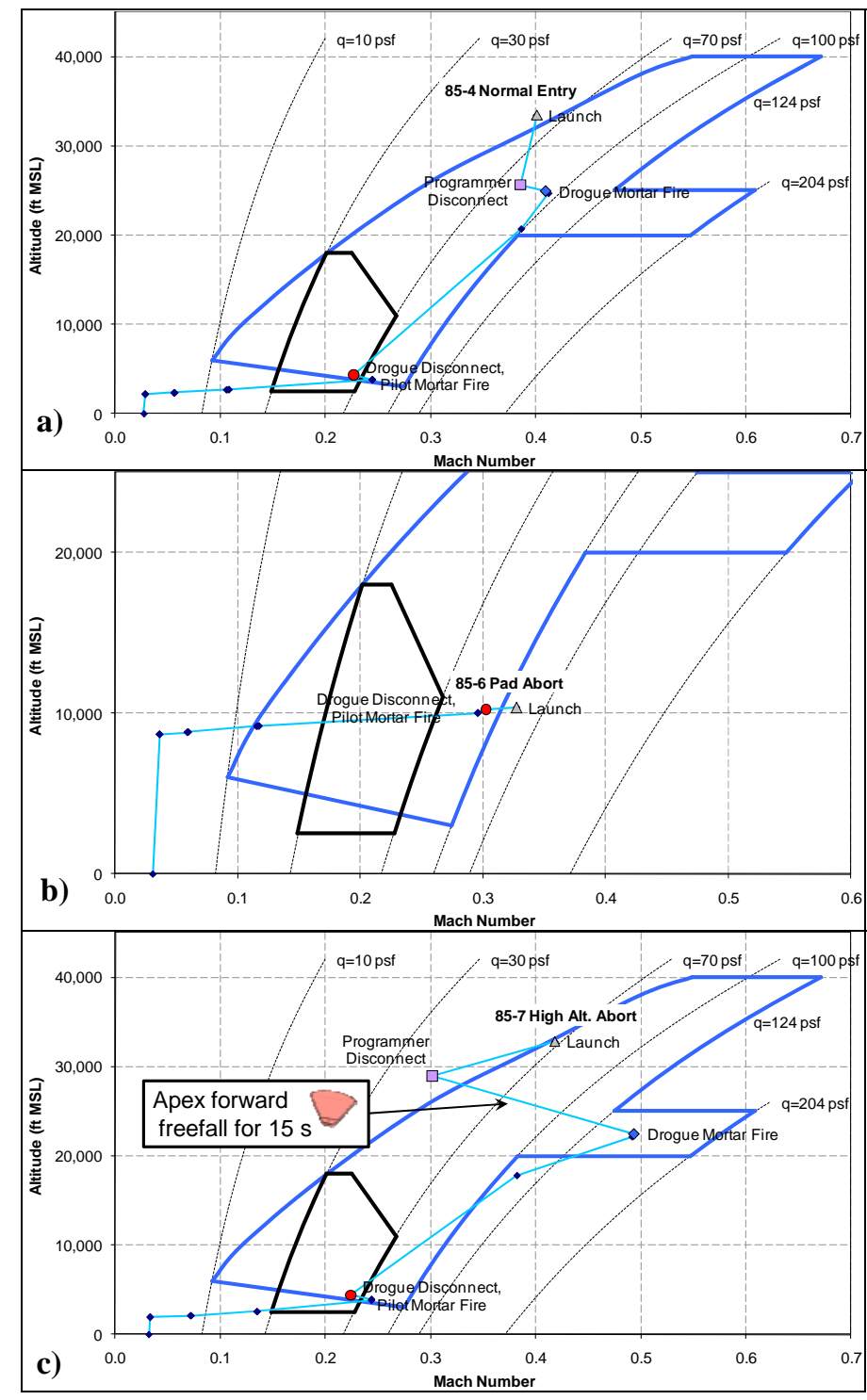

Figure 10. Apollo Block II IC qualification test trajectories using data from Ref. (4). 


\section{Current CPAS Capabilities}

In contrast to the Apollo flight test program, CPAS does not have dedicated aircraft. About two dozen CPAS flight tests have been conducted to date during Generation (Gen) I and II. Each test used commercial or military assets on ranges where test procedures are well established. CPAS Gen I and Gen II tests are summarized in Ref. (5) and Ref. (6), respectively. Preliminary flight test envelopes were determined using a 2-Degree Of Freedom simulation, though preflight trajectories are generally performed with more sophisticated 6-DOF models.

\section{A. Helicopter Drops of Small Drop Test Vehicle (SDTV) and Medium Drop Test Vehicle (MDTV)}

Helicopters can be a relatively inexpensive airframe to lift and release missile-shaped drop test vehicles. A UH-1 can be used to carry a Small Drop Test Vehicle (SDTV) for testing small parachutes such as CPAS Pilots. The $\mathrm{CH}-47$ has been used to test larger parachutes one at a time from a Medium Drop Test Vehicle (MDTV). The maximum reasonable altitude for a safe test is about $14,000 \mathrm{ft}$ MSL depending on the operational limits of the particular helicopter.

The test envelope for this method is shown in Figure 11. Figure 11. CH-47 MDTV test envelope.

Missile-shaped test vehicles can quickly accelerate to a very high dynamic pressure (indicated by the dashed trajectory) but are usually controlled with a programmer parachute to ensure achieving a predictable test point. Even a relatively small programmer can allow the MDTV to get to high dynamic pressures. The right-side boundary assumes the drag area of a CPAS Drogue reefed to $20 \%$, yet the dynamic pressure is above 200 psf. However, the altitude and true airspeeds are far lower than the nominal reentry "shelf" on the CPAS envelope.

Helicopters have also been used to test full-scale spacecraft parachute systems. The Boeing company and Irvin Aerospace (currently Airborne Systems) demonstrated recovery of a mockup of the Propulsion Module for the Evolved Expendable Launch Vehicle by releasing from a CH-47D Chinook. ${ }^{(7)}$ SpaceX tested the parachute recovery system of its Dragon capsule by releasing from an Erikson S-64F Air-Crane helicopter at about 14,000 $\mathrm{ft}^{\left({ }^{(8)}\right.}$ However, the Orion capsule is approximately $30 \%$ heavier than the Dragon capsule, which is beyond the lifting capability of these helicopters. 


\section{B. C-130 LVAD of MDTV/CMS and Parachute Compartment Drop Test Vehicle (PCDTV)}

Another technique is to use the Low Velocity Aerial Delivery (LVAD) method from a C-130 Hercules. This technique has been used successfully several times by CPAS and is illustrated in Figure 12. The MDTV is placed on a Cradle Monorail System (CMS), and the mated assembly is extracted from the C-130. Soon after extraction, the MDTV slides down a rail to separate from the CMS and a programmer parachute is static line deployed. The programmer parachute pulls out the test parachute when it achieves the test condition.

One drawback of the MDTV is that it cannot release a cluster of parachutes, nor deploy using Orion hardware. The Parachute Compartment Drop Test Vehicle (PCDTV) is being designed to fill this need with a similar deployment method, shown in Figure 13. The missile-

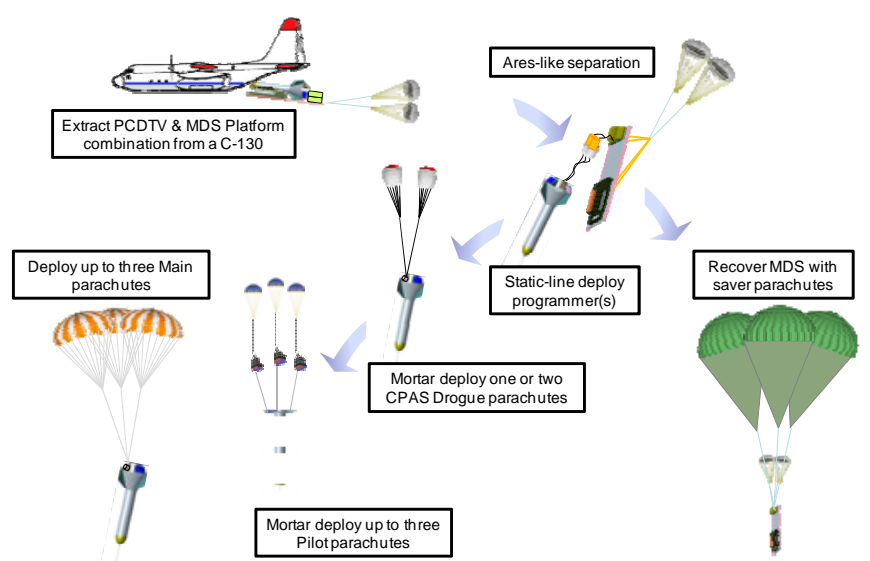

Figure 13. Parachute Compartment Drop Test Vehicle (PCDTV) concept of operations.

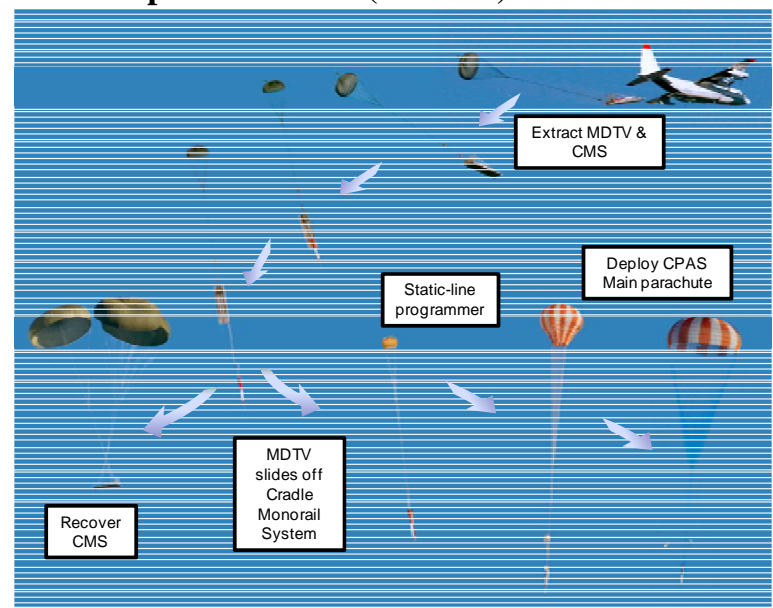

Figure 12. MDTV/CMS concept of operations.

shaped PCDTV will lie on its side on a platform. The PCDTV aft end has a representative Orion parachute compartment, which is slightly truncated to fit within the vertical dimensions of the C-130 cargo bay. The PCDTV will represent most of the important CPAS elements including drogue mortars, pilot parachutes, and the attachment assembly. The PCDTV and cradle will be extracted from a C-130 using standard LVAD techniques and separate in mid-air. A similar concept of operations was used to extract a "Jumbo Dart" test vehicle from a C-17 during the Ares parachute flight test program. ${ }^{(9)}$

The C-130 is a very common and affordable aircraft for testing from either military or commercial sources. The primary limitation of LVAD is the altitude restriction inherent in having an aircrew in an unpressurized environment. LVAD is generally restricted to 25,000 ft and 145 KCAS. The resulting test envelope is shown in Figure 14. The sides of the test envelope are determined by the aerodynamics of the test vehicle and the programmer parachutes used. Low dynamic pressures can be achieved by using two fully open CPAS Drogues. The PCDTV will probably not be allowed to freefall for long due to stability concerns and because its fast acceleration will quickly lose altitude. Therefore, a minimum sized programmer such as a CPAS Drogue reefed at $26 \%$ will probably be used to achieve the test condition.

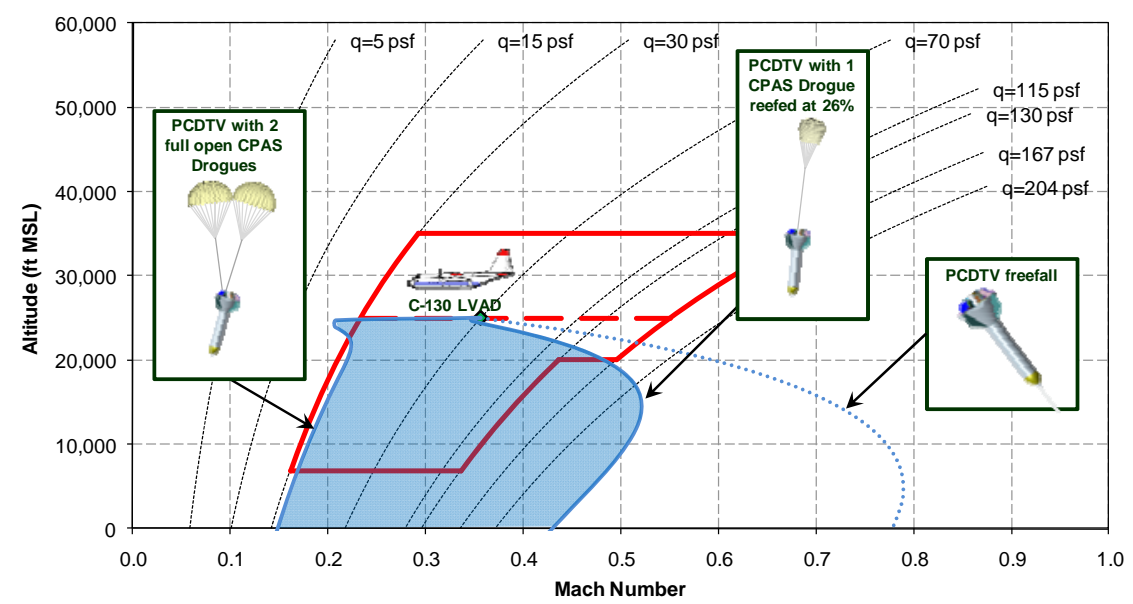

Figure 14. C-130 PCDTV test envelope. 


\section{Orion Parachute Test Vehicle (PTV)}

The CPAS Generation I Parachute Test Vehicle (PTV) was built to test a representative parachute system of the Orion crew module with the full system weight. The PTV outer mold line was intended to represent the CM capsule shape, within the physical limitation of fitting inside the Lockheed C-17 Globemaster parent aircraft. Unfortunately, the PTV was heavily damaged during an unsuccessful Cluster Development Test, CDT-2, on July 31, 2008. ${ }^{(10)}$

The successor test article, PTV2, improves several aspects of the PTV concept of operations. The general method of extraction from the C-17 still uses the Cradle and Platform Separation System (CPSS). As can be seen in Figure 15, fitting the PTV2 and CPSS inside the $\mathrm{C}-17$ requires truncating the Orion height by 33 inches. Consequently, the moments of

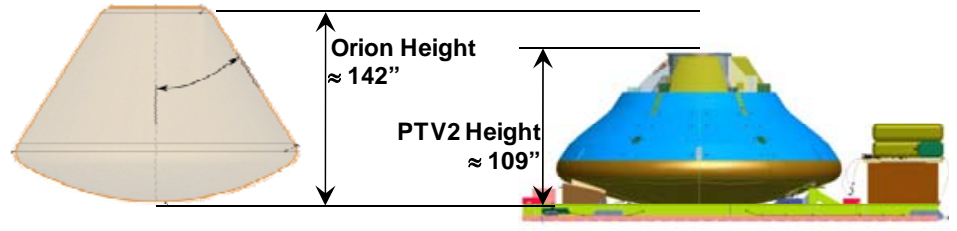

Figure 15. Comparison of Orion and PTV2/CPSS. inertia and Center of Gravity (CG) location will be different than the production Orion.

The concept of operations is shown in Figure 16. The PTV2 is initially securely lashed down to the CPSS. One or two extraction parachutes pull the mated system clear of the C-17. PTV2 will incorporate "smart release" avionics to cut the retention system and at a favorable attitude giving the best chance at positive separation from the CPSS. The PTV2 design will minimize protuberance to reduce the risk of severing a parachute like the first PTV. The CPSS will reposition to a bottom-down attitude under recovery parachutes deployed when the extraction parachute(s) are cut away.

Like the C-130, the C-17 test altitude is limited by the LVAD technique because the aircrew is located in the unpressurized cargo bay. The test envelope for the PTV2, shown in Figure 17, is bounded by the aerodynamics of the PTV capsule shape and the

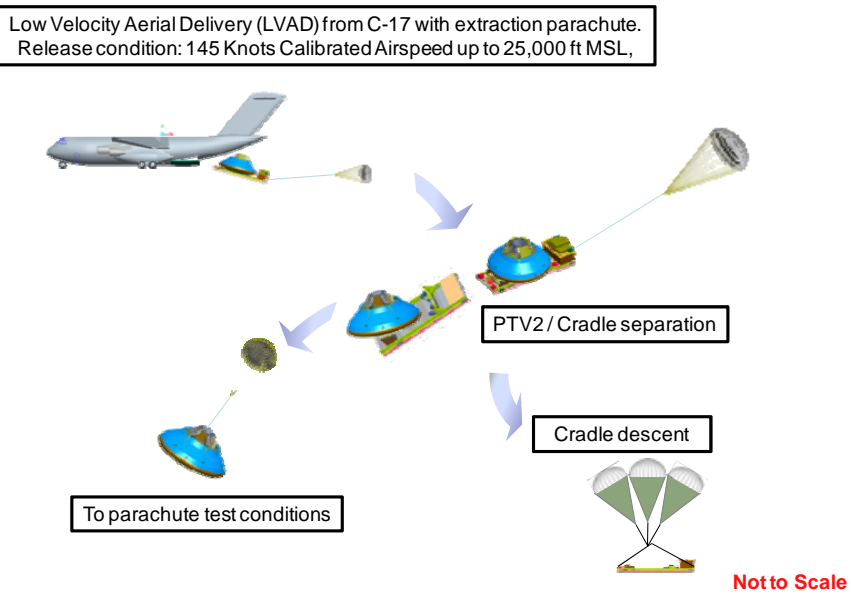

Figure 16. PTV2 concept of operations. programmer parachutes employed. The minimum dynamic pressure curve is defined by two full open CPAS Drogues as programmers. Although freefalling a test vehicle has been used successfully on other test programs and was considered for the original PTV, CPAS disallowed freefalling after CDT-2. The minimum reasonable parachute

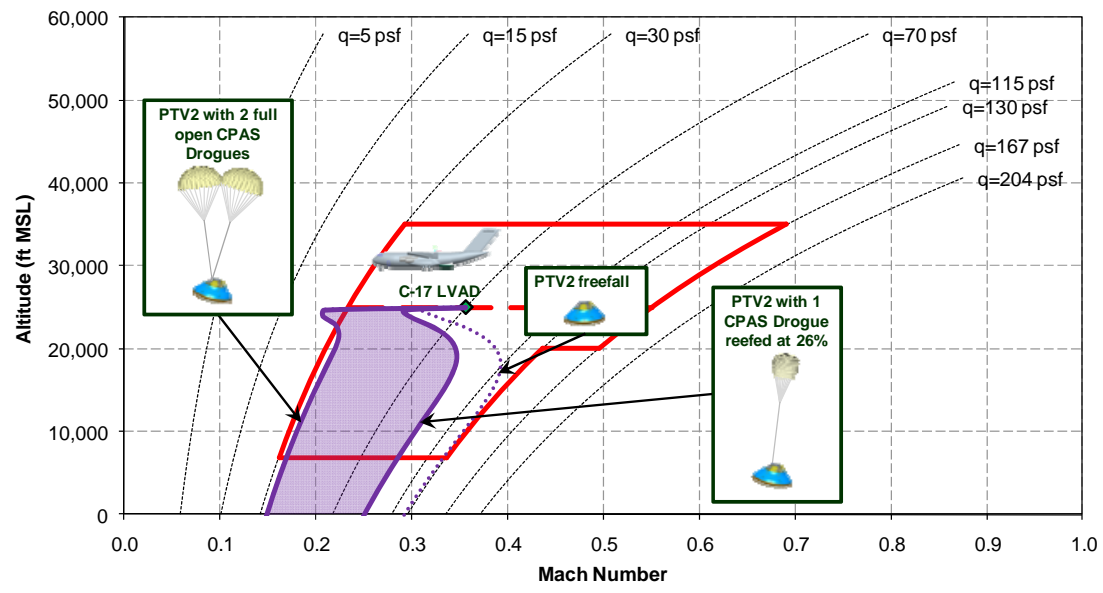
drag area to ensure control of the capsule and remain inflated in the wake is equivalent to a single CPAS Drogue reefed at $26 \%$.

Figure 17. PTV2 test envelope. 


\section{Notional Test Architectures}

The closest approach to the Apollo boilerplate system would be to modify a cargo aircraft in the same way that the C-133 was modified. However, the only cargo aircraft capable of carrying the full-size Orion CM are much larger and less available.

\section{A. Lockheed C-17 Globemaster}

As with the Gen I PTV, an Orion must be truncated in height to fit inside a C-17 for a standard LVAD extraction. However, a CAD model shows that a full size Orion boilerplate can fit inside a C17 if the cargo ramp were removed, as illustrated in Figure 18. As with the C-133, a custom internal truss would probably be required to hold the capsule in place.

Unfortunately,

C-17 airframes are currently in high demand so modifying an airframe, even temporarily, seems logistically unfeasible.

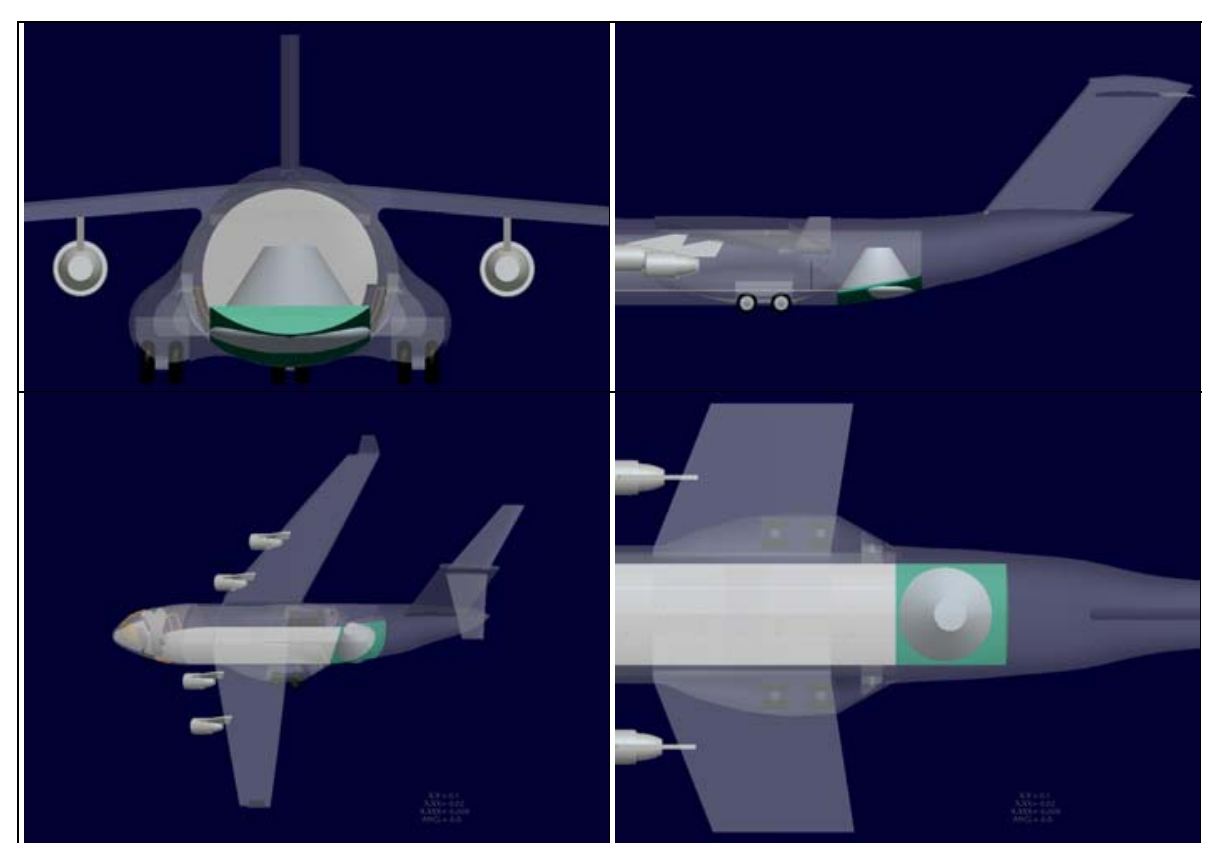

Figure 18. Fit check of Orion boilerplate inside modified C-17 parent

\section{B. Boeing C-5 Galaxy}

A rudimentary check of dimensions shows that a modified Boeing C-5 Galaxy would also be able to accommodate Orion in the same way. Very few C-5 airframes are still operational.

For many years during the Space Shuttle program, two U.S. Air Force C-5s were available to fly at the pleasure of NASA should the orbiter perform a trans-Atlantic abort. These would be used to ferry equipment to mate the orbiter to the Shuttle Carrier Aircraft (SCA), for a return flight. As these aircraft were scheduled to be mothballed, NASA investigated using them for flight tests. However, the structure of the C-5 has always been an issue ${ }^{(11)}$, and the cargo ramp was determined unsuitable for LVAD of CPAS loads. Removing the ramp for boilerplate drops would eliminate that issue. Nevertheless, CPAS never had a sufficient budget for aircraft maintenance of what is becoming a rare aircraft. 


\section{Antonov An-124}

Many cargo aircraft developed by the former Soviet Union are available through commercial companies. They are used to ferry large and unusual cargos all over the world in a timely fashion. The Antonov An-124 (code named "Condor" by NATO) is the second largest aircraft in the world after the related An-225. The An-124 can fit a full-size Orion CM inside the cargo bay, as illustrated in Figure 19. Although the military version of the An-124 was designed for airdrop capability, the former Soviet Union never exercised that option beyond a short development test program.

The short ramp and clamshell doors on the An-124, seen in Figure 20, offer an

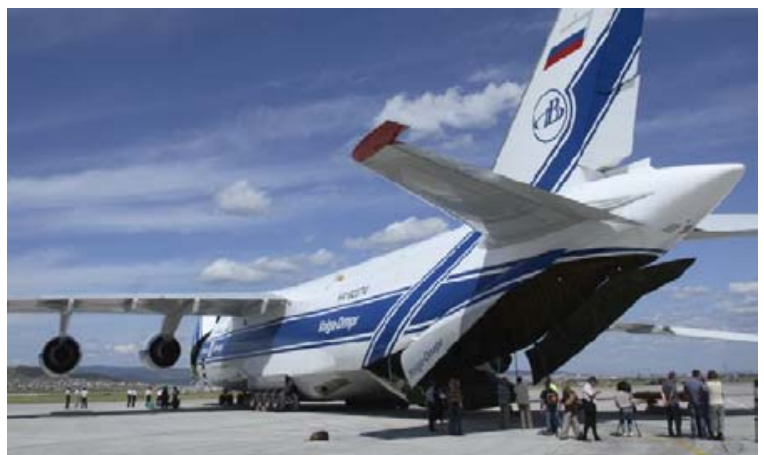

Figure 20. An-124 ramp and clamshell doors. advantage and disadvantage. When the side doors are open, the shortened ramp offers a free space for the capsule to drop similar to the Apollo from a C-

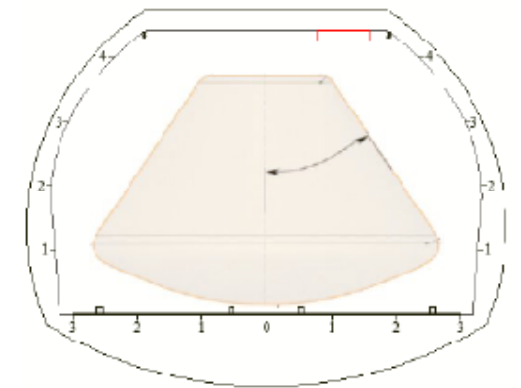

Figure 19. Orion boilerplate inside An-124 cargo hold, courtesy Volga-Dnepr Group. 133. However the structural integrity of the side doors might be compromised by opening in flight, so their temporary removal might be required.

Another advantage of the An-124 is the internal crane system which is rated to lift weights several times heavier than Orion and can even be used to shift cargo during flight to meet aircraft stability requirements. Several engineering issues remain to be resolved. For example, the Orion boilerplate must be stowed rigidly during emergency landings and the separation technique must be examined.

The cockpit of the An-124 can remain pressurized for the aircrew while the rear doors are open. If the release system could be automated, this airframe has the capability to release from significantly higher altitudes than a C-17 or C-130. Ultimately, the positioning and operational costs of this aircraft make its use by CPAS unlikely.

\section{Iluhshin Il-76}

The Iluyshin Il-76 (named "Candid” by NATO) was the platform of choice for air delivery by the former Soviet Union. An Il-76 would not be able to fit a boilerplate Orion shape, but it could accommodate a missile-shaped parachute compartment vehicle of even larger diameter than the C-130 can carry. A comparison of the Il-76 dimensions relative to other aircraft is shown in Figure 21. However, the dimensional advantage over the C-130 is outweighed by aircraft cost. The entire cabin is unpressurized during cargo extraction, so it offers no altitude advantage over the C-130. Further, commercial aircrews generally do not have experience in aerial delivery from this airframe.

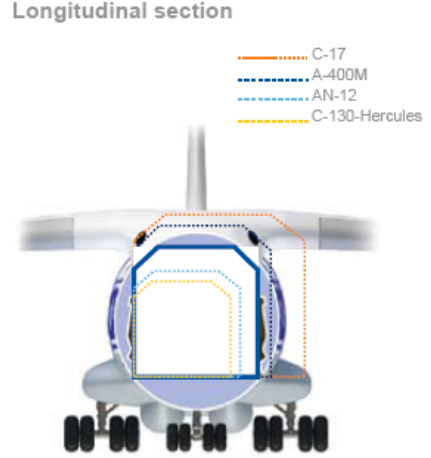

Figure 21. Il-76 cargo bay size relative to other aircraft. 


\section{E. Boeing B-52 Stratofortress}

NASA has had much experience with using B-52 airframes for flight testing parachute systems, including Apollo, Space Shuttle Solid Rocket Booster (SRB) ${ }^{(12)}$, and X-38 Crew Return Vehicle. ${ }^{(13)}$ The Orion outer mold line is far too large to fit under the wing of a B-52, and unlike Apollo, the parachute compartment diameter is too large to fit inside the bomb bay. CPAS considered a missile-shaped vehicle with a representative parachute compartment, called the Large Drop Test Vehicle (LDTV) for releasing from the wing of a B-52.

Several development issues would have to be resolved. The B-52 wing might not be able to handle the full Orion weight. Store separation certification would have to be conducted, which might easily grow into a program unto itself.

Another consideration is aircraft cost and availability. Most NASA B-52 tests used a specific airframe based out of Dryden known by its tail number of 008. Despite its age, that particular aircraft had seen fewer flight hours than most B-52s in the Air Force fleet. Unfortunately, that airframe was retired in 2004.

Several important modifications were made on NASA 008. The starboard inboard flap was fixed in the horizontal position to accommodate test vehicles. A notch was cut into the flap to allow for a vertical stabilizer on the $\mathrm{X}-15$. This became important for stabilizing the SRB Drop Test Vehicle, seen in Figure 22. ${ }^{(14)}$ It is not feasible to expect similar accommodation on Air Force fleet aircraft.

The $\mathrm{X}-37$ was expected to be drop tested from a B-52 and an extensive integration and separation program was performed. ${ }^{(15)}$ A novel parachute separation technique was developed to prevent X-37 recontact. $^{(16)}$ However, the B-52 was ultimately abandoned in favor of White Knight 1 for cost and technical reasons (see section IV-G).

Assuming a release point seen on other programs of Mach 0.8 at $50,000 \mathrm{ft}$, the LDTV could easily get to almost anywhere on the CPAS Drogue deploy envelope, as

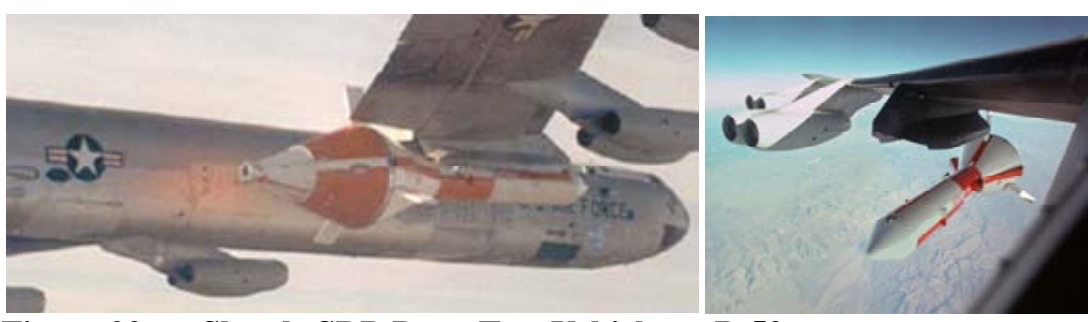

Figure 22. Shuttle SRB Drop Test Vehicle on B-52.

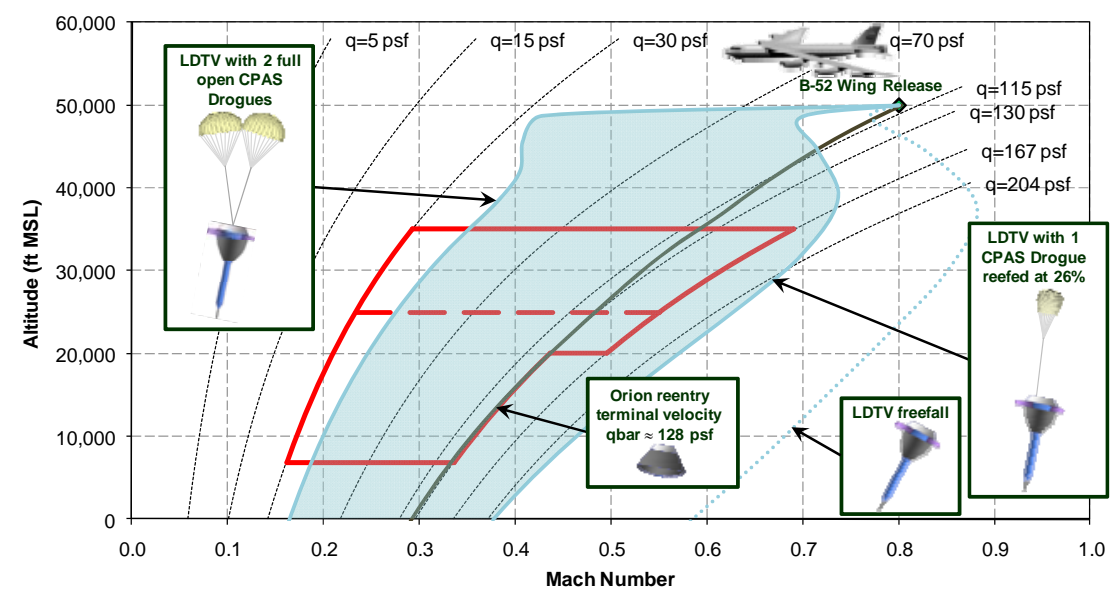

Figure 23. Large Drop Test Vehicle (LDTV) test envelope from B-52. seen in Figure 23. 


\section{F. Shuttle Carrier Aircraft (SCA)}

In 1974 NASA considered using 3 to 5 Air Force-owned C-5A Galaxy aircraft for transporting the Space Shuttle Orbiter. Concerns over Air Force restrictions and the relative scarcity of C-5As drove selection of more plentiful used 747 airframes. These two 747s are known as the Shuttle Carrier Aircraft (SCA). NASA 905 is a Boeing 747123 purchased from American Airlines in 1974. NASA 911 is a Boeing 747-100SR ("Short Range"), purchased from Japan Airlines in $1990 .{ }^{(17)}$ At the conclusion of the Space Shuttle program, the fate of these two aircraft is uncertain.

The two SCA were built with a feature sometimes called a "fifth engine” pylon. ${ }^{(18)}$ Commercial $747 \mathrm{~s}$ might

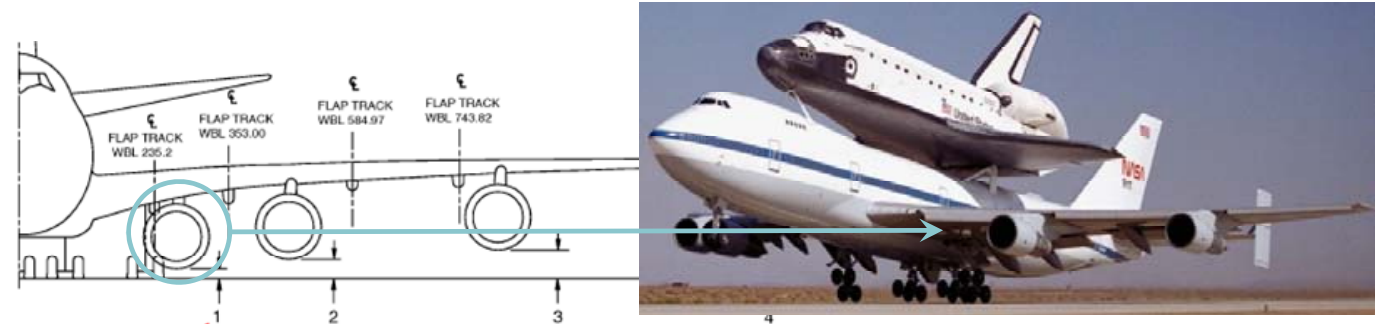

Figure 24. 747 Shuttle Carrier Aircraft (SCA) have a "fifth engine” pylon mount.

be required to carry an inert engine to remote airports for servicing use on another 747 . This might accommodate a wing separation vehicle such as the LDTV. A diagram and potential location on the SCA is shown in Figure 24. However, the cost of modification and certification would have to be weighed against using a B-52. The low wing, landing gear, and flap track fairings limit test vehicle geometry. The capabilities at release are not yet known.

Another option would be to modify the aircraft structure to create a cavity for releasing a boilerplate capsule, similar to the Apollo method. There is precedent to making massive structural modifications to 747 aircraft. In the late 1970s Boeing proposed using cargo 747 aircraft to carry cruise missiles on rotary launchers and air launch through an aft door. ${ }^{(19)}$ In 2005 Boeing modified three 747-400s into Large Cargo Freighters to carry ferry an entire fuselages of the 787 "Dreamliner" from suppliers to assembly facilities. ${ }^{(20)}$ NASA modified a 747SP to carry an airborne telescope called SOFIA. ${ }^{(21)}$ However, any modification of the pressure vessel is well beyond the current CPAS budget.

\section{G. Scaled Composites White Knight}

Rather than retrofitting an existing aircraft, the only way to ensure a carrier vehicle meets requirements is to design a new aircraft. During the early development of the Space Transportation System, several designs included releasing a reusable spacecraft from a carrier aircraft in flight, though such concepts have been on NASA drawing boards since at least the 1960s. ${ }^{(17)}$ The requirements for high altitude separation invariably lead to an aircraft with twin fuselages and very high aspect ratio wings, not unlike the Scaled Composites White Knight 1 and White Knight 2.

White Knight 1 was ultimately selected to release the X-37 vehicle, shown in Figure 25, as a less expensive alternative to the B-52. However, White Knight 1 is limited in payload weight and test article dimensions. Although

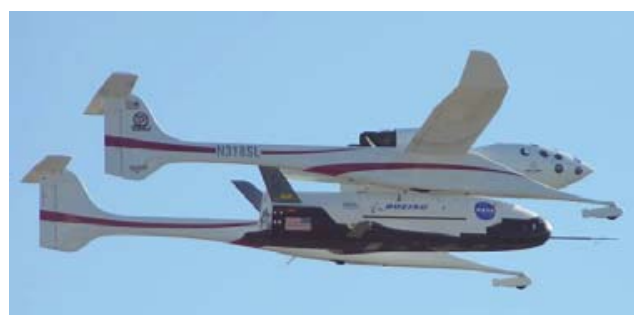

Figure 25. Scaled Composites White Knight 1 carying X-37.

White Knight 2 has a larger size and payload capacity, it is unknown if any of the full-weight CPAS test articles would be compatible. 


\section{H. Balloon Systems}

CPAS is currently scheduled to use balloons for the high-altitude portion of its test program. There is precedent for flight testing parachute systems under capsule shapes from a high-altitude balloon. The European Space Agency (esa) performed qualification flights for the Atmospheric Reentry Demonstrator (ARD) by dropping from balloons at $23 \mathrm{~km}$ ( 75,500 $\mathrm{ft}$ ). The ARD had a shape and mass similar to Apollo. The system was stabilized in flight with ballast and spring-damper system during an extended freefall period of 49.5 seconds. ${ }^{(22)}$ The retracted damper system can be seen in Figure 26. The test parachutes functioned and the test article was recovered in the Mediterranean.

However, an Orion-sized vehicle would be more limited in altitude due to its weight. High

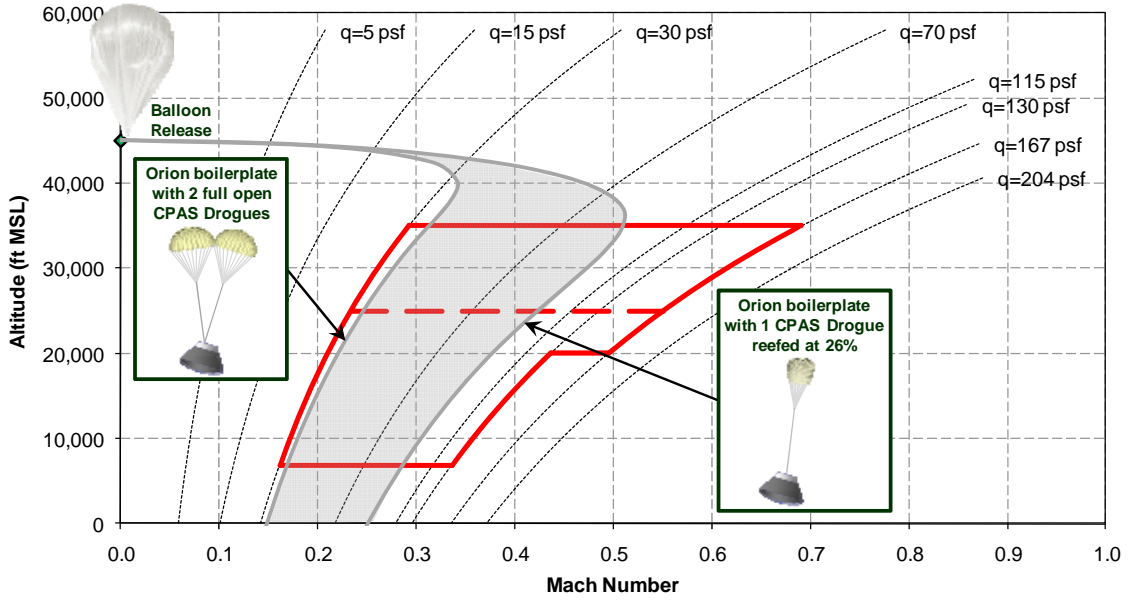

Figure 27. Conceptual envelopes for Orion boilerplate dropped from high altitude balloon.

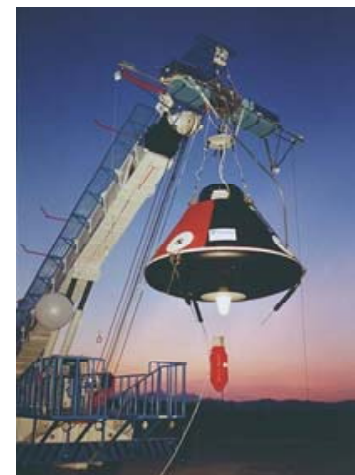

balloons

expand to

massive

volumes

as a

function

Figure 26.

Reentry

preparing ascent.

of local

density. The release ceiling is currently being determined, but a conceptual envelope for an Orion boilerplate is shown in Figure 27. Even from a release at $45,000 \mathrm{ft} \mathrm{MSL}$, the minimal programmer parachute prevents Orion from achieving the "shelf."

In order to get to the "shelf" either the programmer must be eliminated or the test article needs to be more streamlined. CPAS could replicate the ARD ballast system in lieu of a programmer. However, the current approach is to supplement boilerplate drops with some tests using the more streamlined PCDTV from a balloon. This allows the PCDTV to achieve higher dynamic pressures at higher altitudes than from a C130. The resulting envelopes are shown in Figure 28.

One of the limiting factors of this technique is the large test range required. A survey of potential test ranges is underway.

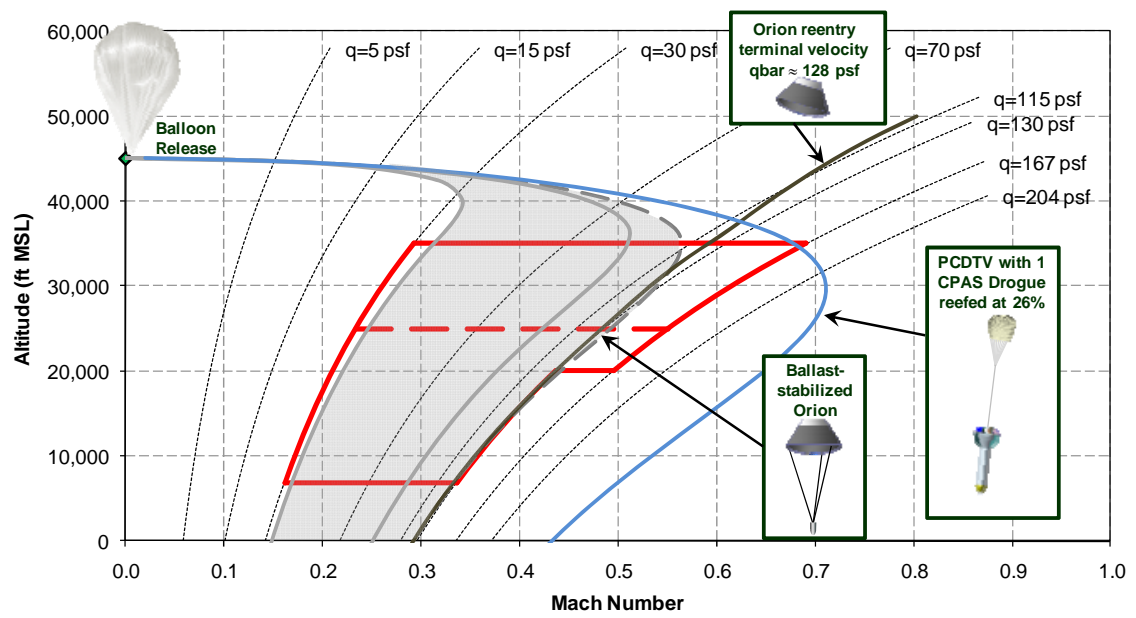

Figure 28. Conceptual envelopes for ballast-stabilized Orion boilerplate or PCDTV dropped from high altitude balloon. 


\section{Test Range Limitations}

Two CPAS tests were conducted at the Naval Air Weapons Station (NAWS) China Lake near Ridgecrest, CA. The majority of the CPAS flight tests to date were conducted at the Robby Drop Zone (DZ) at Yuma Proving Ground (YPG) in Yuma, AZ.* Both of these facilities are in a desert environment with different low altitude atmospheric properties than the ocean. Early Orion designs allowed for landing on dry ground, but the current architecture calls for splashdown in the ocean.

Range rules at YPG require all parachutes to land within the DZ. A thorough description can be found in the paper describing the CPAS footprint tool. ${ }^{(23)}$ Of particular concern would be for programmer parachutes cut away at high altitude to be carried by the prevailing winds on to nearby highway 95, interfering with civilian traffic. The test article should land on the cleared area, both for range safety, and because this area has been cleared of vegetation which might damage test parachutes. Should any of the parachutes fail to function, it is essential that the ballistic trajectory of the test article stay out of the keep out zones occupied by ground cameras and their operators. Further, no significant masses, such as ballast or extraction sleds are allowed to freefall to the ground.

High altitude flight tests will therefore need to be conducted at alternative test ranges. Other sites are currently being investigated.

\section{Conclusion}

Flight testing of the entire CPAS Drogue deploy envelope will require certain compromises due to technical, cost, and schedule limitations. The Apollo program was able to test a functional system with representative trajectories including failure modes. However, the size and weight of Orion make many of the same test techniques prohibitive. Further, the CPAS budget does not allow for operating dedicated aircraft, which rules out making useful modifications that could increase the fidelity of testing.

A combination of several options is under consideration.

\section{Acknowledgments}

The authors wishes to acknowledge John Scoggins, formerly of CPAS, for CAD modeling Orion inside a C-17. The Volga-Dnepr Unique Air Cargo, Inc. provided information and photographs for the An-124 and Il-76.

\section{References}

1. Sebastian, Thomas and Tolson, Robert. Methods for the Determination of Aerodynamic Parameters and Trajectory Reconstruction of the Orion Command Module from Scale Model Aeroballistic Flight Data. January 5 8, 2009. 47th AIAA Aerospace Sciences Meeting, Orlando, Florida. AIAA paper 2009-882.

2. Apollo Summary, a Historical Perspective (Presentation). CPAS Manager's Review. May 29, 2008.

3. Development Tests Apollo ELS Increased Capability Program (scan of Appendix E foldout).

4. Murray, H. L. Parachute Subsystem Apollo Block II Increased Capability Earth Landing System Final Report of the Series 85 Qualification Drop Tests, Volume I. Newbury Park, CA : Northrop Corporation, Ventura Division, August 1968. NVR-6070 A, NASA-CR-152750.

5. Bledsoe, Kristin, Englert, Megan, Morris, Aaron, and Olmstead, Randy. Overview of the Crew Exploration Vehicle Parachute Assembly System (CPAS) Generation I Main and Cluster Development Test Results. May 4 - 7, 2009. 20th AIAA Aerodynamic Decelerator Systems Technology Conference and Seminar, Seattle, Washington. AIAA paper 2009-2940.

6. Morris, Aaron, et. al. Summary of CPAS Gen II Parachute Performance. May 23 - 26, 2011. 21st AIAA Aerodynamic Decelerator Systems Technology Conference and Seminar, Dublin, Ireland. (Submitted for publication).

7. Delurgio, Philip R., et al. Recovery System for the Evolved Expendable Launch Vehicle. 1997. AIAA paper 971513.

8. Space Exploration Technologies Corporation. SpaceX press releases. [Online] August 12, 2010. [Cited: September 7, 2010.] http://www.spacex.com/press.php?page=20100820.

\footnotetext{
${ }^{*}$ The DZ is referred to as Robby when the aircraft flies Northward, as was the case in all these tests, or as La Posa if
} the aircraft flies Southward. 
9. King, Ron, Hengel, John E. and Wolf, Dean. Ares I First Stage Booster Deceleration System: An Overview. May 4 - 7, 2009. 20th AIAA Aerodynamic Decelerator Systems Technology Conference and Seminar, Seattle, Washington. AIAA paper 2009-2984.

10. Machin, Ricardo A. and Evans, Carol T. Cluster Development Test 2 an Assessment of a Failed Test. May 4 7, 2009. 20th AIAA Aerodynamic Decelerator Systems Technology Conference and Seminar, Seattle, WA. AIAA paper 2009-2902.

11. Badrocke, Mike and Gunston, Bill. Boeing Aircraft Cutaways: The History of Boeing Aircraft Company. New York : Banres \& Noble Books, 2001. ISBN 0-7607-2500-4.

12. Moog, R. D., Sheppard, J. D. and Kross, D. A. Space Shuttle Solid Rocket Booster Decelerator Subsystem Drop Test Results. AIAA Paper No. 79-0463.

13. Bennett, Thomas W. and Fox, Roy. Design, Development \& Flight Testing of the NASA X-38 7,500 ft2 Parafoil Recovery System. May 19 - 22, 2003. 17th AIAA Aerodynamic Decelerator Systems Technology Conference and Seminar, Monterey, CA. AIAA paper 2003-2107.

14. Aerodynamic Analysis of the Solid Rocket Propellant Booster Deceleration Subsystem Drop Tests. November 1978. NASA-CR-170670, TR-230-1942.

15. Paez, Carlos A. The Development of the X-37 Re-Entry Vehicle. July 11 - 14, 2004.40 th AIAA/ASME/SAE/ASEE Joint Propulsion Conference and Exhibit, Fort Lauderdale, FL. AIAA paper 2004-4186.

16. Whitmore, Steven A., et al. Development and Testing of a Drogue Parachute System for X-37 ALTV / B-52H Separation. Reno, NV : s.n., January 5 - 8, 2004. 42nd AIAA Aerospace Sciences Meeting and Exhibit. AIAA paper 2004-873.

17. Jenkins, Dennis R. Space Shuttle: The History of the National Transporation System, The First 100 Missions. Stillwater, MN : Voyageur Press, 2001. ISBN 0-9633974-5-1.

18. Boeing Commercial Airplane Company. 747 Airplane Characteristics Airport Planning. [Online] May 1984. http://www.boeing.com/commercial/airports/acaps/747_123sp.pdf. D6-58326.

19. FLIGHT International. November 5, 1977. p. 1345.

20. 747 Large Cargo Freighter. Boeing corporate web site. [Online] http://www.boeing.com/news/releases/2005/photorelease/q1/pr_050222g-1.html.

21. Stratospheric Observatory for Infrared Astronomy. SOFIA Science Center. [Online] [Cited: October 6, 2010.] http://www.sofia.usra.edu.

22. Rives, J. and Leveugle, T. Atmospheric Re-entry Demonstrator Descent and Recovery Sub-System Qualification Test Capsule Stabilization during the Free Fall Phase. 1997. AIAA paper 97-1440.

23. Bledsoe, Kristin J. Development of the Sasquatch Drop Test Footprint Tool. May 23 - 26, 2011. 21st AIAA Aerodynamic Decelerator Systems Technology Conference and Seminar, Dublin, Ireland. (Submitted for publication). 